\title{
Analisis Directional Coupler Sebagai Pembagi Daya untuk Mode TE
}

\author{
Agus Rubiyanto, ${ }^{*}$ Agus Waluyo, Gontjang Prajitno, dan Ali Yunus Rohedi
}

Jurusan Fisika, FMIPA, Institut Teknologi Sepuluh Nopember, Kampus ITS Sukolilo, Surabaya 60111

\begin{abstract}
Intisari
Directional coupler merupakan piranti optik yang tersusun atas dua pandu gelombang sejajar dengan salah satu fungsinya sebagai pembagi daya. Parameter utama pembagian daya ini adalah panjang kopling $\left(\mathrm{L}_{c}\right)$, yang diselesaikan menggunakan persamaan matrik karakteristik lapis jamak. Jenis film yang digunakan adalah planar graded index berprofil $\operatorname{sech}^{2}$ dengan peningkatan indeks bias 0,07 , untuk panjang gelombang $1,33 \mu \mathrm{m}$. Pembagian daya optik antar kanal bisa terjadi dengan memvariasi panjang kopling. Untuk jarak gab 1,5 $\mu \mathrm{m}$ pada $\mathrm{Z}=232 \mu \mathrm{m}$ semua daya dipindah ke kanal kedua, sedangkan pada $\mathrm{Z}=174 \mu \mathrm{m}$, perbandingan daya antara kanal satu dan kanal dua adalah 25 berbanding 75. Untuk pembagi daya dengan keluaran yang sama antar kanal, dibutuhkan panjang interaksi sebesar $116 \mu \mathrm{m}$. Pada panjang interaksi sebesar $58 \mu \mathrm{m}$, daya pada kanal pertama tiga perempat dari daya masukan, seperempat sisa dayanya ditransmisikan ke kanal kedua.
\end{abstract}

KATA KUNCI: directional coupler, pembagi daya, panjang kopling

\section{PENDAHULUAN}

Tahun 1960 merupakan awal berkembangnya sistem komunikasi menggunakan gelombang optik sebagai gelombang pembawa, dengan fiber optik sebagai media transmisinya [1]. Penampilan pertama laser rubi di tahun 1960 diikuti dengan demonstrasi kerja laser pada piranti semikonduktor pada tahun 1962 merupakan langkah awal dari operasi laser pada temperatur ruang dengan waktu pakai yang panjang.

Dewasa ini, tantangan bagi sistem komunikasi untuk informasi super high way menuntut akan kecepatan laju data yang tinggi [2]. Penggunaan perangkat elektronik yang ada di pasaran rasanya kurang bisa dihandalkan untuk menutupi tuntutan tersebut, sehingga diperlukan adanya sistem komunikasi optik denggan perangkat coupling dan switching yang memadahi. Directional coupler merupakan salah sisitem pandu gelombang tersusun atas dua pandu gelombang kanal sejajar yang mampu mentransmisikan informasi melalui banyak saluran atau lebih dikenal dengan sebutan multiplexing. Salah satu sifat dari directional coupler adalah kemampuannya memindahkan daya ke kanal kedua ketika kanal pertama ditransmisikan gelombang optik. Hal ini dikarenakan terjadinya kopling dalam directional coupler yang mempengaruhi perambatan daya gelombang optik sepanjang kanal. Dengan membatasi panjang kopling, directional coupler dapat juga digunakan sebagai pembagi daya optik. Dalam sistem komunikasi optik pembagian daya menjadi peranan yang penting ketika akan dilakukan pentransmisian gelombang pada dua tempat yang berbeda.[3]

*E-MAIL: arubi@physics.its.ac.id

\section{TINJAUAN PUSTAKA}

\section{A. Pandu Gelombang Planar}

Pemanduan cahaya pada pada pandu gelombang akan terjadi bila $n_{f}>n_{s} \geq n_{k}$, karena gelombang optik yang terpandu dalam lapisan film merupakan gelombang optik yang mengalami pantulan internal total. Menurut hukum Snellius, pantulan internal hanya terjadi, bila sudut datang gelombang $(\theta)$ harus lebih besar dari sudut kritis $\left(\theta_{c}\right)$ pada kedua bidang batas.

Gelombang optik terpandu dinyatakan dengan persamaan Helmholz untuk moda TE sebagai: [4]

$$
\frac{\partial^{2} E_{y}}{\partial x^{2}}+\left(n^{2} k_{o}^{2}-\beta^{2}\right) E_{y}=0
$$

dengan $\left(n^{2} k_{o}^{2}-\beta^{2}\right)$ adalah tetapan propagasi gelombang optik sepanjang bahan, dan $\mathrm{k}_{0}$ adalah tetapan propagasi dalam ruang hampa, dan $\beta$ adalah konstanta propagasi dalam arah perambatan.

Pola medan listrik untuk setiap moda terpandu pada tiap-

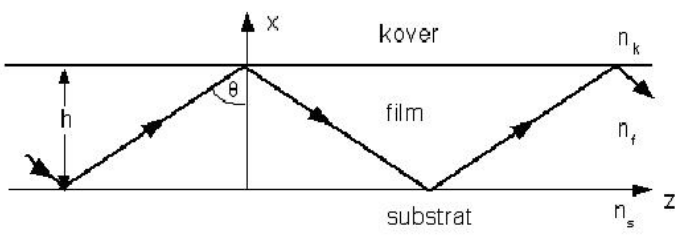

Gambar 1: Sinar moda terpandu sepanjang pandu gelombang optik 
tiap lapisan adalah :

$$
\begin{aligned}
& E_{y k}=E_{k} \exp \left[-\gamma_{k}(x-h]\right), \text { untuk } \mathrm{h}<\mathrm{x},(\text { kover }) \\
& E_{y f}=E_{f} \exp \left(\kappa_{f} x-\phi_{s}\right), \text { untuk } 0<\mathrm{h}<\mathrm{x},(\text { film }) \\
& E_{y s}=E_{s} \exp \left(\gamma_{s} x\right), \text { untuk } \mathrm{x}<0, \text { (substrat) }
\end{aligned}
$$

dengan $E_{k}, E_{f}$, dan $E_{s}$ menyatakan amplitudo medan listrik pada daerah kover, film dan substrat. Sedangkan konstanta propagasi gelombang optik sepanjang lapisan kover $\left(-\gamma_{k}\right)$, lapisan film $\left(\kappa_{f}\right)$ dan lapisan substrat $\left(-\gamma_{s}\right)$ berturut-turut adalah :

$$
\begin{aligned}
-\gamma_{k}^{2} & =n_{k}^{2} k_{o}^{2}-\beta^{2} \\
\kappa_{f}^{2} & =n_{f}^{2} k_{o}^{2}-\beta^{2} \\
-\gamma_{s}^{2} & =n_{s}^{2} k_{o}^{2}-\beta^{2}
\end{aligned}
$$

Pada pandu gelombang planar tak simetri (indeks bias lapisan kover dan indeks bias lapisan substrat berbeda) berlaku:

$$
\begin{aligned}
V & =k_{o} h \sqrt{n_{f}^{2}-n_{s}^{2}} \\
a & =\frac{n_{s}^{2}-n_{k}^{2}}{n_{f}^{2}-n_{s}^{2}} \\
b & =\frac{N^{2}-n_{s}^{2}}{n_{f}^{2}-n_{s}^{2}}
\end{aligned}
$$

$\mathrm{V}$ adalah frekuensi ternormalisasi, a menyatakan faktor ketaksimetrian indeks bias substrat kover, sedangkan b menyatakan normalisasi indeks bias efektif dan $\mathrm{N}$ adalah indeks bias efektif yang nilainya adalah $N=\beta k_{o}$.

Untuk menghitung harga $\beta$ yang terdapat di dalam $\gamma_{k}, \kappa_{f}$ dan $\gamma_{s}$ ini terlebih dahulu dinyatakan dalam besaran ternormalisasi (besaran tanpa dimensi)

$$
V \sqrt{1-b}-\tan ^{-1} \sqrt{\frac{b}{1-b}}-\tan ^{-1} \sqrt{\frac{b+a}{1-b}}=m \pi
$$

sedangkan harga $\beta$ dapat dicari dari persamaan

$$
\beta=k_{o} \sqrt{b\left(n_{f}^{2}-n_{s}^{2}\right)+n_{s}^{2}}
$$

\section{B. Metode Matrik Karakteristik Lapis Jamak}

Pada pandu gelombang planar, pada masing-masing lapisan berlaku persamaan

$$
\begin{aligned}
H_{x} & =-\left(\frac{\beta}{\omega \mu}\right) E_{y} \\
H_{z} & =-\frac{1}{j \omega \mu} \frac{\partial E_{y}}{\partial x} \\
E_{y} & =-\frac{j}{\omega \epsilon} \frac{\partial E_{y}}{\partial x}-\frac{\beta}{\omega \epsilon} H_{x}
\end{aligned}
$$

Dengan mendefinisikan variabel $\mathrm{U}=E_{y}$ dan $\mathrm{V}=\frac{\partial E_{y}}{\partial x}$ persamaan Helmholz menjadi [5]

$$
\frac{\partial^{2} U}{\partial x^{2}}+\kappa^{2} U=0
$$

dengan solusi

$$
\begin{aligned}
& U=A \sin (\kappa x)+B \cos (\kappa x) \\
& V=\frac{\partial U}{\partial x}=\kappa A \cos (\kappa x)-\kappa B \sin (\kappa x)
\end{aligned}
$$

dan akan didapatkan bentuk matrik secara umum,bila tebal setiap lapisan $h_{i}=x_{i}-x_{i-1}$, demikian pula tetapan propagasi setiap lapisan $\kappa_{i}=\sqrt{k_{o}^{2} n_{i}^{2}-\beta^{2}}$ dengan $\mathrm{i}=1,2,3 . . \mathrm{n}$,:

$$
\left[\begin{array}{l}
U_{i} \\
V_{i}
\end{array}\right]=M_{i}\left[\begin{array}{l}
U_{i-1} \\
V_{i-1}
\end{array}\right]
$$

$M_{i}$ menyatakan matrik karakteristik untuk setiap lapisan ke-i dari lapisan film pandu gelombang, yaitu :

$$
M_{i}=\left[\begin{array}{cc}
\cos \left(\kappa_{i} h_{i}\right) & \frac{\sin \left(\kappa_{i} h_{i}\right)}{\kappa_{i}} \\
-\kappa_{i} \sin \left(\kappa_{i} h_{i}\right) & \cos \left(\kappa_{i} h_{i}\right)
\end{array}\right]
$$

Hubungan antara substrat dan kover ditunjukkan dalam bentuk matrik

$$
\left[\begin{array}{l}
A_{k} \\
B_{k}
\end{array}\right]=\left[\begin{array}{cc}
1 & 1 \\
-\gamma_{k} & \gamma_{k}
\end{array}\right]\left[\begin{array}{ll}
m_{11} & m_{12} \\
m_{21} & m_{22}
\end{array}\right]\left[\begin{array}{cc}
1 & 1 \\
-\gamma_{s} & \gamma_{s}
\end{array}\right]\left[\begin{array}{l}
A_{s} \\
B_{s}
\end{array}\right]
$$

dan dapat dinyatakan sebagai

$$
\left[\begin{array}{l}
A_{k} \\
B_{k}
\end{array}\right]=\left[\begin{array}{ll}
M_{11} & M_{12} \\
M_{21} & M_{22}
\end{array}\right]\left[\begin{array}{l}
A_{s} \\
B_{s}
\end{array}\right]
$$

harga $\mathrm{b}$ dapat ditentukan dengan memberi nol pada $M_{22}$.

\section{Directional Coupler}

Directional coupler adalah piranti optik yang tersusun atas dua pandu gelombang kanal sejajar yang saling berdekatan dalam orde panjang gelombang optik yang ditanam pada satu substrat. Struktur geometri Directional coupler ditunjukkan pada Gambar 2 dengan s adalah lebar gap (yaitu jarak antar kanal), h adalah lebar masing-masing kanal sepanjang arah lateral, d adalah kedalaman setiap kanal, dan $\mathrm{Z}$ adalah panjang interaksi. Kedalaman dan lebar lateral masing-masing kanal dirancang hanya dapat memandu gelombang optik moda tunggal (single mode).

Pada lebar gap yang kecil gelombang evanescent moda dasar dari kedua kanal sepanjang daerah gap tersebut saling berinteraksi menghasilkan efek kopling atau efek gandengan, yang kekuatannya tergantung pada panjang gelombang optik 


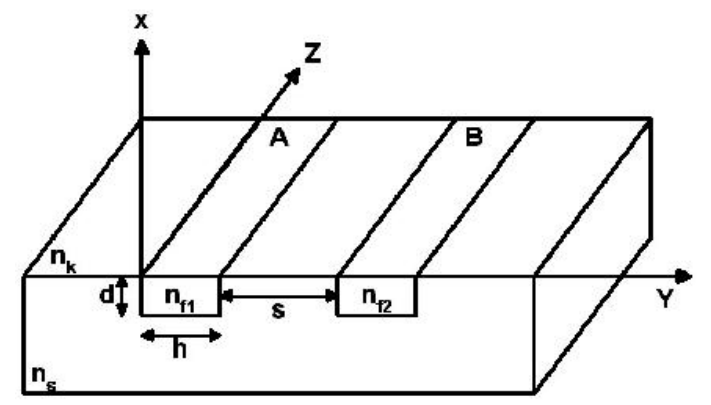

Gambar 2: Directional coupler yang terdiri dari dua pandu gelombang A dan B.

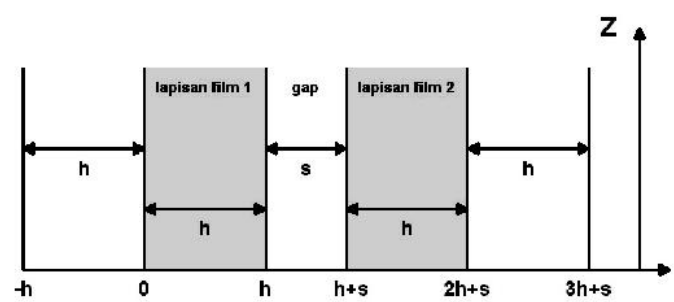

Gambar 3: Directional coupler dilihat dari atas

yang merambat di dalamnya. Timbulnya kopling berpengaruh terhadap perambatan daya gelombang optik disepanjang kanal sehingga gelombang optik yang masuk pada salah satu kanal, pada jarak tertentu yang disebut jarak kopling semua dayanya dipindahkan ke kanal yang lain. Sehingga dengan karakteristik seperti ini maka directional coupler dapat dirancang sebagai perangkat WDM, pemisah polarisasi, saklar optik dan sebagainya [3]. Directional coupler bila dilihat dari atas diperlihatkan pada Gambar 3.

Proses perpindahan daya gelombang optik antar kanal dapat dijelaskan menggunakan teori moda tergandeng (couple mode theory). Berdasarkan teori ini bila lebar gap cukup besar maka gelombang evanescent moda dasar dari kedua kanal

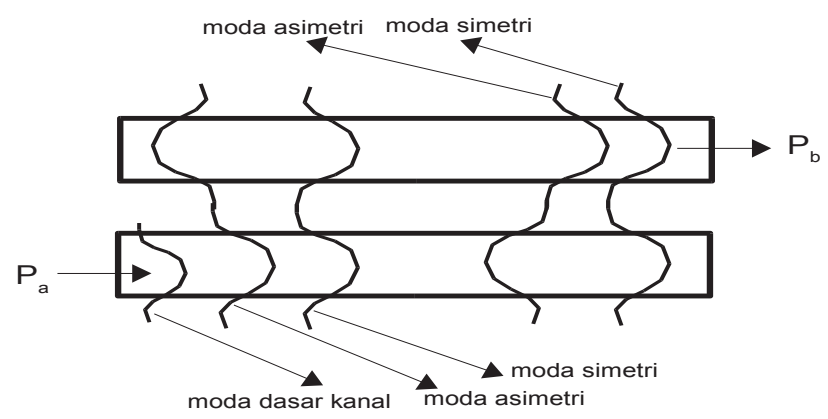

Gambar 4: Diskripsi teori moda terkopel terhadap perambatan gelombang optik dalam directional coupler (dilambangkan dengan A dan B) di sepanjang daerah gap tidak menimbulkan kopling, sehingga pada masing-masing kanal gelombang optik pada moda dasar tersebut dapat merambat secara individu. Sebaliknya bila lebar gap kedua kanal sangat kecil maka gelombang evanescent moda dasar di sepanjang daerah gap tersebut saling memberikan gangguan (perturbation), kopling antar keduanya menyebabkan amplitudo gelombang optik yang merambat pada masing-masing kanal berubah sepanjang jarak rambatnya.

Jika ke dalam kanal pertama ditransmisikan gelombang optik, maka sebagian berkasnya ter-evanescent ke kanal kedua. Berkas pada kanal ke tersebut terpandu dan sebagian berkasnya akan ter-evanescent ke kanal pertama lagi. Overlaping antar gelombang evanescent yang saling berinterferensi mengakibatkan terjadinya proses perpindahan daya antar pandu gelombang kanal penyusun directional coupler. Jika interferensinya saling menguatkan akan terbentuk gelombang optik simetri dengan tetapan perambatan $\beta_{s}$, dan ketika interferensinya saling melemahkan maka akan terbentuk gelombang optik asimetri dengan tetapan perambatannya $\beta_{a}$. Dalam proses perambatannya kedua moda tersebut saling bersuperposisi. Sampai pada jarak $L_{c}$ (panjang kopling) puncak superposisi pola medannya terletak pada kanal kedua dan semua dayanya dipindahkan ke kanal kedua dan ketika jaraknya dua kali panjang kopling $\left(z=2 L_{c}\right)$ semua dayanya terkopel kembali ke kanal pertama, demikian seterusnya.

Amplitudo moda setiap pandu gelombang dinyatakan sebagai :

$$
\begin{aligned}
& \psi_{1}=\frac{1}{2}\left(e^{j \beta_{s} z}+e^{j \beta_{a} z}\right) \\
& \psi_{2}=\frac{1}{2}\left(e^{j \beta_{s} z}-e^{j \beta_{a} z}\right)
\end{aligned}
$$

dan daya yang merambat pada setiap kanal adalah :

$$
\begin{aligned}
& P_{1}=\psi_{1} \psi_{1}^{*} \\
& P_{2}=\psi_{2} \psi_{2}^{*}
\end{aligned}
$$

Dalam penelitian ini directional coupler menggunakan film planar graded indeks dengan indeks bias berprofil $\mathrm{sech}^{2}$, dimana profil ini merupakan profil pandu gelombang yang telah dipabrikasi oleh Bauman L, dkk (1994). Persamaan untuk profil $\operatorname{sech}^{2}$ adalah sebagai berikut:

$$
n^{2}(x)-n_{s}^{2}+2 n_{s} \operatorname{sech}^{2}\left(-\frac{2 x}{h}\right)
$$

dengan $\Delta n$ adalah peningkatan indeks bias. Sedangkan indeks bias efektif $(\mathrm{N})$ dinyatakan dengan persamaan :

$$
N^{2}=b\left(2 n_{s} \Delta n\right)+n_{s}^{2}
$$

\section{HASIL DAN PEMBAHASAN}

\section{A. Hubungan antara Lebar gab dan Tetapan Propagasi}

Parameter-parameter yang dipergunakan meliputi bahan yang digunakan adalah $\mathrm{LiNbO}_{3}$ indeks bias substrat $n_{s}=2,1$, 


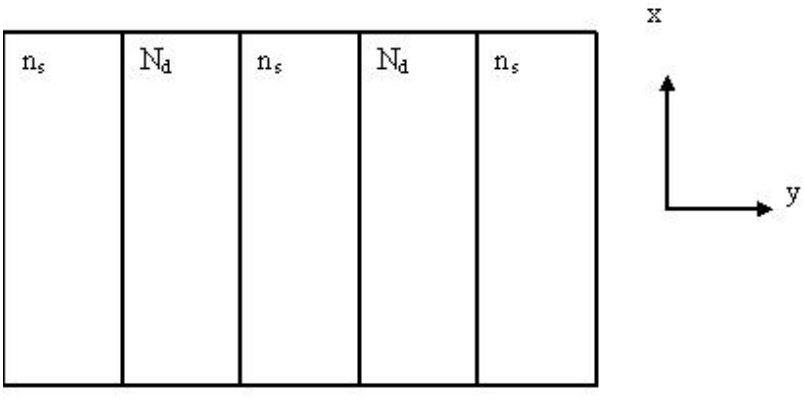

Gambar 5: Susunan pandu gelombang arah lateral

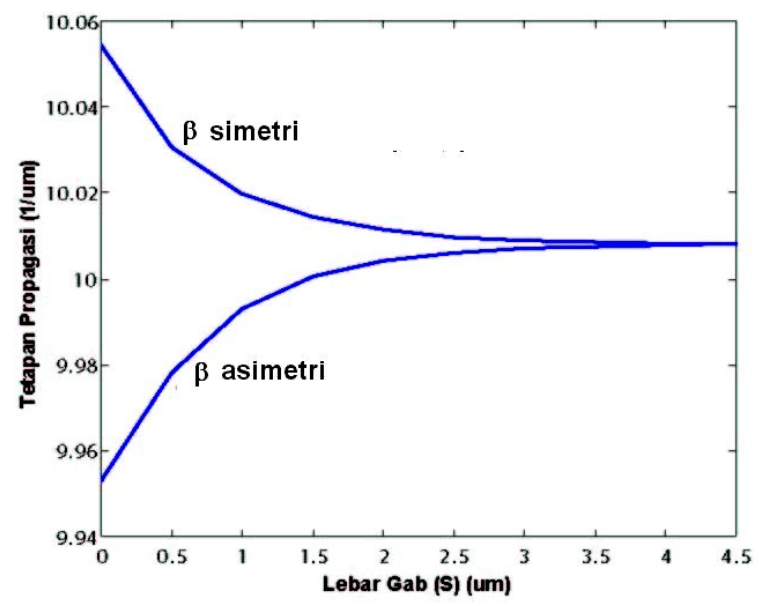

Gambar 6: Pengaruh antara lebar gab dan tetapan propagasi

peningkatan indeks biasa 0.07 (yaitu proses difusi titanium pada $\mathrm{LiNbO}_{3}$ selama 4 jam dengan temperatur $1000^{\circ} \mathrm{C}$ ), $[1,3]$. Panjang gelombang yang dipergunakan $1,33 \mu \mathrm{m}$, dengan ketebalan lapisan film arah lateral $(\mathrm{h})=1,2 \mu \mathrm{m}$.

Bagian terpenting dari simulasi dengan menggunakan Matlab 5.5 [6] ini adalah menentukan panjang $L_{c}$. Jika panjang $L_{c}$ sudah diketahui maka dengan membatasi panjang $L_{c}$ akan terjadi pembagian daya directional coupler pada kanal satu dan kanal dua. Untuk menentukan panjang $L_{c}$ terlebih dahulu menentukan indeks bias efektif ternormalisasi arah kedalaman $\left(b_{d}\right)$ (lihat Gambar 5). Harga $b_{d}$ ditentukan dengan metode secant. Dari hasil $b_{d}$ tersebut bisa untuk menentukan indeks bias efektif arah kedalaman $N_{d}$, dengan $N_{d}=\sqrt{b_{b}\left(2 n_{s} d_{n}\right)+n_{s}^{2}}$. Nilai $N_{d}$ tersebut digunakan untuk menentukan indeks bias efektif ternormalisasi arah lateral $\left(b_{l}\right)$ dengan metode secant pula.

Harga tetapan konstanta propagasi $(\beta)$ baik yang simetri maupun yang asimetri didapat dari subtitusi $b_{l}$, kedalam persamaan $\beta=k_{o} \sqrt{b_{1}\left(n_{f}^{2}-n_{s}^{2}\right)+n_{s}^{2}}$ sehingga panjang kopling $\left(L_{c}\right)$ bisa diketahui dari persamaan $L_{c}=\frac{\pi}{\Delta \beta}$, dengan $\Delta \beta=\beta_{s}-\beta_{a}$. Hubungan antara lebar gab dan tetapan propagasi dijelaskan pada Gambar 6 .

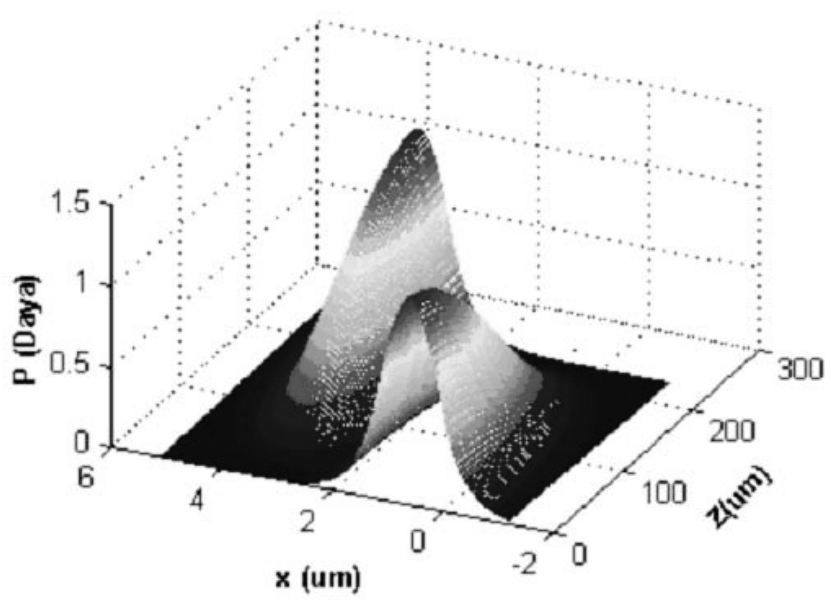

Gambar 7: Seluruh cahaya berpindah dari kanal pertama ke kanal ke dua.

Dari Gambar (6) diketahui, bahwa semakin besar nilai gap(S) tetapan propagasi moda asimetri semakin besar sedangkan tetapan propagasi moda simetri semakin kecil, hingga pada nilai jarak gap 4,5 $\mu \mathrm{m}$ nilai tetapan propagasi keduanya sama. Pada kondisi ini panjang coupling $\left(L_{c}\right)$ sangat besar, karena nilai $\Delta \beta$ bernilai sangat kecil, atau dengan kata lain panjang couplingnya tak terhingga. Artinya gelombang terpandu pada masing-masing kanal yang diberi daya masukan, dan directional coupler tidak berfungsi sebagai pembagi daya.

\section{B. Visualisasi Perambatan Gelombang Optik Dalam Directional Coupler Sebagai Pembagi Daya}

Visualisasi perambatan gelombang optik untuk lebar gab $(\mathrm{S})=1.5 \mu \mathrm{m}$ dijelaskan pada beberapa visualisasi berikut ini. Daya optik ditransmisikan pada kanal pertama directional coupler. Melalui proses interaksi moda tergandeng, seluruh daya berpindah pada kanal ke dua ketika jarak interaksi sebesar $232 \mu \mathrm{m}$ seperti diperlihatkan pada Gambar 7. Jarak interaksi ini disebut panjang coupling.Pada jarak interaksi sebesar $174 \mu \mathrm{m}$, directional coupler berfungsi sebagai devais pembagi daya optik dengan perbandingan 25 dengan 75 seperti yang diperlihatkan pada Gambar 8.Devais optik yang sering dipakai adalah devais $3 \mathrm{~dB}$ coupler yang dapat membagi daya $50 \%$ pada masing-masing kanal. Keadaan ini dicapai pada jarak interaksi $116 \mu \mathrm{m}$ (lihat Gambar 9).

\section{Pengaruh Lebar Gap Terhadap Jarak Dimana Daya Terbagi}

Hubungan antara lebar gap (S) dengan jarak interaksi pada arah perambatan $\mathrm{Z}$ diperlihatkan pada Gambar 10, dimana daya terbagi sebagai fungsi $\mathrm{S}$ dan $\mathrm{Z}$. Panjang daya terbagi meningkat dengan seiring dengan bertambahnya lebar gap (S). 


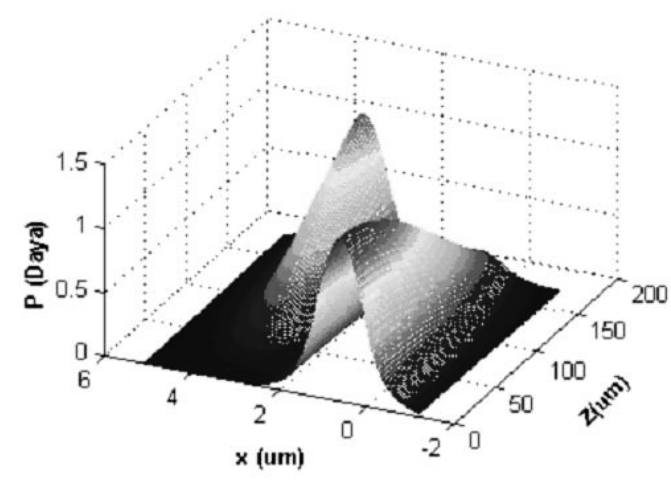

Gambar 8: Distribusi intensitas optik dari dua pandu gelombang dengan perbandingan pada pandu gelombang keluaran kanal pertama 25 dan kanal kedua 75

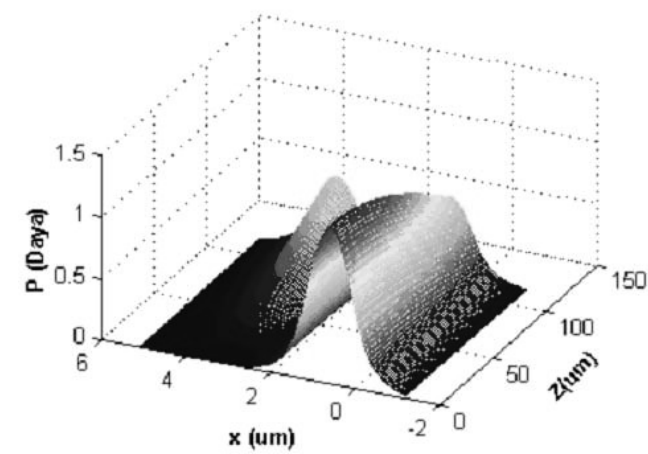

Gambar 9: Intensitas cahaya optik dibagi dua dengan prosentase sama untuk kanal pertama dan kanal ke dua pada jarak interaksi 116 $\mu \mathrm{m}$

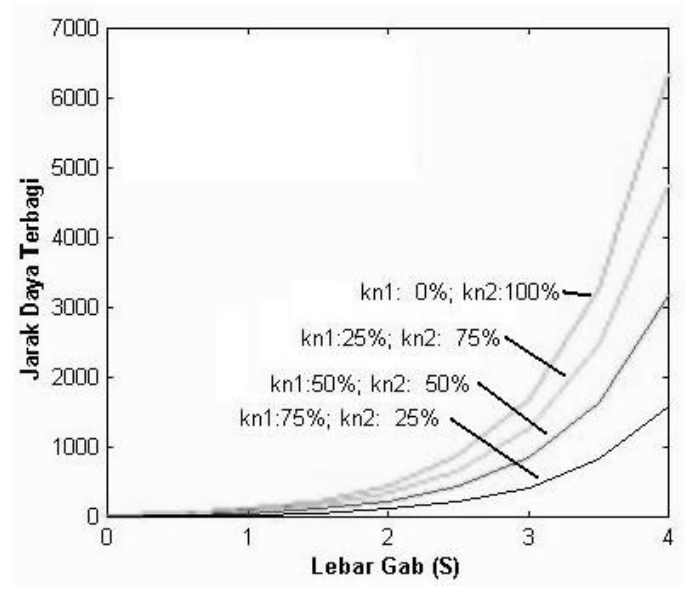

Gambar 10: Hubungan antara Lebar Gap (S) dan Jarak Daya Terbagi.

\section{KESIMPULAN}

Berdasarkan hasil analisis visualisasi directional coupler sebagai pembagi daya, dapat diambil kesimpulan sebagai berikut: untuk jarak antara pandu gelombang yang besar tidak terjadi kopling antar kanal, sehingga daya hanya merambat pada kanal pertama dan tidak ter-evanescent ke kanal ke dua. Pembagian daya bisa dilakukan dengan memberi batas panjang $L_{c}$. Semakin besar lebar gap maka semakin besar pula panjang $L_{c}$. Untuk merancang suatu divais pembagi daya dapat ditentukan terlebih dahulu prosentase pembagi, kemudian jarak antar pandu gelombang dan juga jarak daya terbagi yang diinginkan.
[1] A.Y.Rohedi,Perancangan Directional Coupler Untuk Aplikasi WDM Struktur 4X4, Tesis Magister Teknik bidang Optoelektronika dan Aplikasi Laser, Universitas Indonesia, Jakarta.(1997)

[2] Harsoyono, Majalah Iptek, Edisi 08, Th. VII, pp. 1-8,(1998)

[3] H.Nishihara,M. HarunaT.,Suhara,Optical Integrated Circuits, R. R. Donelley and Sons Company,(1989)

[4] H.Kolgenik,Theory of Dielectric Waveguide In :Guided-Wave
Optoelektronics, Eds. Theodor Tamir, Springer-Verlag, New York,(1990).

[5] H.P.Uranus, J.E.Batubara, Optronika, No.1, Th. 1, pp. 3442(1997).

[6] D.Hanselman,B.Littlefield, Matlab Bahasa Komputasi Teknis, Penerbit Andi, Yogyakarta,(2001) 